\title{
Hydraulic alumina as an inorganic binder for extruding and sintering $\mathrm{Si}_{3} \mathrm{~N}_{4}$ ceramics
}

\author{
Takaaki NAGAOKA, ${ }^{* \dagger}$ Cihangir DURAN, ${ }^{* * *}$ Hasan GOCMEZ, ${ }^{* * * * *}$ Hideki HYUGA* and Koji WATARI ${ }^{*}$ \\ *National Institute of Advanced Industrial Science and Technology (AIST), \\ 2266-98 Anagahora, Shimoshidami, Moriyama-ku, Nagoya 463-8560, Japan \\ ** Meteksan Defense Industry Inc., Turkey \\ *** Dumlupinar University, Turkey
}

\begin{abstract}
The present work describes the effect of hydraulic alumina (HA) as both a new inorganic binder for extrusion and a sintering additive for silicon nitride $\left(\mathrm{Si}_{3} \mathrm{~N}_{4}\right)$ ceramics. The addition of small amount of $\mathrm{HA}$ imparted flowability and rigidity to the $\mathrm{Si}_{3} \mathrm{~N}_{4}$ bodies, and could reduce the amount of use of the conventional organic binder to $1 / 3$. Under optimum processing conditions such as amount of the organic binder and water, rods and tubes were successfully extruded using a single screw extruder. Sintered specimens have achieved a relative density of $99 \%$ after sintering at 1700 and $1800^{\circ} \mathrm{C}$ for $4 \mathrm{~h}$. Mechanical properties of the sintered $\mathrm{Si}_{3} \mathrm{~N}_{4}$ prepared by the body with $\mathrm{HA}$ were almost the same as the ones prepared using the conventional additives such as the conventional organic binder and sintering additive, that is, Young's modulus $>300 \mathrm{GPa}$ and $\mathrm{H}_{\mathrm{v}}>1330$. These results indicate that small amount of $\mathrm{HA}$ addition contributes not only to impart the plasticity but also act as the sintering additive for $\mathrm{Si}_{3} \mathrm{~N}_{4}$ ceramics.
\end{abstract}

(C2012 The Ceramic Society of Japan. All rights reserved.

Key-words : Extrusion, Silicon nitride, Hydraulic alumina, Inorganic binder, Hydration, Flowability, Rigidity, Sintering

[Received February 22, 2012; Accepted May 25, 2012]

\section{Introduction}

Extrusion is one of the widely used ceramic forming techniques for producing objects having extended length scales with constant cross sections such as rods, tubes and honeycomb structures. Usually, the extrusion technique requires the use of organic binders in body formulations in order to impart flow ability and rigidity (plasticity). ${ }^{1)-6)}$ However, addition of the organic binder needs both debinding process and exhaust gas treatment process, during which, in turn, large amount of thermal energy is consumed. Therefore, a reduction in the use of organic binders in forming technique is required.

Recently, we have developed a new water-based inorganic binder system for extrusion. ${ }^{7), 8)}$ This binder system is composed of alumina hydrates such as pseudo-boehmite and bayerite formed by hydration of hydraulic alumina (HA). Under optimum processing conditions such as HA content, water content and curing period, the green bodies with HA have a good plasticity. ${ }^{8)}$ Then, HA is expected as one of the inorganic binder for extrusion for some kind of ceramics with $\mathrm{Al}_{2} \mathrm{O}_{3}$ component.

Silicon nitride $\left(\mathrm{Si}_{3} \mathrm{~N}_{4}\right)$ ceramics have been widely identified as one of the promising engineering ceramics, because of their superior mechanical properties. However, densification of $\mathrm{Si}_{3} \mathrm{~N}_{4}$ ceramics is difficult due to its high degree of covalent bonding between silicon and nitrogen atoms. Oxide additives such as $\mathrm{MgO},{ }^{9)} \mathrm{Al}_{2} \mathrm{O}_{3}-\mathrm{Y}_{2} \mathrm{O}_{3}{ }^{10)}$ and rare-earth oxides ${ }^{11)}$ are generally used as sintering additives to promote densification by the liquidphase sintering. ${ }^{12)}$ On the other hand, in the process of preparing $\mathrm{Si}_{3} \mathrm{~N}_{4}$ paste for forming, use of water was studied from the view point of eco-friendly ceramic processing. For example, water-based $\mathrm{Si}_{3} \mathrm{~N}_{4}$ paste with organic binder or clay mineral was

Corresponding author: T. Nagaoka; E-mail: t.nagaoka@aist.go.jp prepared for extrusion technique. ${ }^{13), 14)}$ In the new water-based inorganic binder system, employing $\mathrm{HA}$ and water, the hydrated $\mathrm{HA}$ is converted into $\alpha-\mathrm{Al}_{2} \mathrm{O}_{3}$ at high temperature. Therefore, HA behaves as not only an inorganic binder for extrusion but also a sintering additive. More importantly, the addition of small amount of HA reduces the addition of the conventional organic binder.

In this study, $\alpha-\mathrm{Al}_{2} \mathrm{O}_{3}$ was replaced by $\mathrm{HA}$ for $\mathrm{Si}_{3} \mathrm{~N}_{4}$ with $\mathrm{Al}_{2} \mathrm{O}_{3}-\mathrm{Y}_{2} \mathrm{O}_{3}$ as sintering additive. Then, effect of small amount of $\mathrm{HA}$ addition on extrusion of $\mathrm{Si}_{3} \mathrm{~N}_{4}$ ceramics was studied in order to apply a new inorganic green binder widely. Furthermore, sintering and characterization of the extruded samples (e.g., densification and mechanical properties) were carried out to compare the results with the ones prepared using the conventional organic binder and sintering additive.

\section{Experimental procedure}

\subsection{Sample Preparation}

The starting materials used in this study were $\alpha-\mathrm{Si}_{3} \mathrm{~N}_{4}$ (SN E-10, oxygen content $<2$ mass $\%, \beta<5$ mass $\%$, specific surface area of $11.1 \mathrm{~m}^{2} / \mathrm{g}$, UBE Industries, Ltd., Tokyo, Japan), $\mathrm{Y}_{2} \mathrm{O}_{3}$ (RU-P, purity of $>99.9 \%$, Shin-Etsu Chemical Co. Ltd., Tokyo, Japan), $\mathrm{HA}\left(\rho-\mathrm{Al}_{2} \mathrm{O}_{3}\right.$ and $\chi-\mathrm{Al}_{2} \mathrm{O}_{3}$ mixed powder) (BK-105, L.O.I.: $5.3 \%, \mathrm{Al}_{2} \mathrm{O}_{3}: 99.7 \%$ purity, with a mean particle size of $6 \mu \mathrm{m}$, Sumitomo Chemical Co., Ltd., Tokyo, Japan), $\alpha-\mathrm{Al}_{2} \mathrm{O}_{3}$ (TMDAR, purity of $>99.99 \%$, specific surface area of 14.5 $\mathrm{m}^{2} / \mathrm{g}$, Taimei Chemicals Co., Ltd., Nagano, Japan), and methyl cellulose (MC) (SM-1500, Shin-Etsu Chemical, Co., Ltd., Tokyo, Japan). In these materials, $\mathrm{Y}_{2} \mathrm{O}_{3}$ and $\mathrm{HA}$ were added as sintering additives and $\mathrm{MC}$ was used as organic binder for extrusion. Before preparing the $\mathrm{Si}_{3} \mathrm{~N}_{4}-\mathrm{Y}_{2} \mathrm{O}_{3}-\mathrm{HA}$ mixed powder, the HA powder was ground with methanol using a planetary ball mill to break down agglomerates and reduce particle size $\left(\mathrm{d}_{50}=1.4\right.$ 
Table 1. Composition of the silicon nitride bodies prepared for this Study

\begin{tabular}{|c|c|c|c|c|c|c|c|c|c|c|}
\hline \multirow[t]{2}{*}{ Material } & \multicolumn{10}{|c|}{ Samples (mass part) } \\
\hline & SHA-1 & SHA-2 & SHA-3 & SHA-4 & SHA-5 & SHA-6 & SA-1 & SA-2 & SA-3 & SA-4 \\
\hline $\mathrm{Si}_{3} \mathrm{~N}_{4}$ & 90 & 90 & 90 & 90 & 90 & 90 & 90 & 90 & 90 & 90 \\
\hline $\mathrm{Y}_{2} \mathrm{O}_{3}$ & 5 & 5 & 5 & 5 & 5 & 5 & 5 & 5 & 5 & 5 \\
\hline Hydraulic alumina* & 5.72 & 5.72 & 5.72 & 5.72 & 5.72 & 5.72 & & & & \\
\hline $\mathrm{Al}_{2} \mathrm{O}_{3}$ & & & & & & & 5 & 5 & 5 & 5 \\
\hline Methyl cellulose & 0 & 0.5 & 1 & 0 & 0.5 & 1 & 2 & 2 & 3 & 4 \\
\hline $\mathrm{H}_{2} \mathrm{O}$ & 42.5 & 42.5 & 42.5 & 50 & 50 & 50 & 42.5 & 42.5 & 42.5 & 42.5 \\
\hline
\end{tabular}

SHA, Silicon nitride body with $\mathrm{Y}_{2} \mathrm{O}_{3}$, hydraulic alumina and methyl cellulose.

SA, Silicon nitride body with $\mathrm{Y}_{2} \mathrm{O}_{3}, \alpha-\mathrm{Al}_{2} \mathrm{O}_{3}$ and methyl cellulose.

*, 5.72 mass parts HA corresponds to 5 mass parts $\alpha-\mathrm{Al}_{2} \mathrm{O}_{3}$.

$\mu \mathrm{m})$. This preparation procedure of the ground HA powder was described in our previous work. ${ }^{7)}$ The $\mathrm{Si}_{3} \mathrm{~N}_{4}-\mathrm{Y}_{2} \mathrm{O}_{3}-\mathrm{HA}$ mixed powder was prepared by using a ball mill in a plastic container with silicon nitride balls in the presence of methanol at $20 \mathrm{rpm}$ for 1 day. Then, the mixtures were dried at $60^{\circ} \mathrm{C}$ in a vacuum followed by screened through a \#150-mesh sieve. The mixed powder and the MC in a plastic bag were shaken by hand for 5 min to prepare the mixture. Distilled water was added to this powder mixture and mixed in a mini shaker (AR-250, Thinky, Osaka, Japan) at $2500 \mathrm{rpm}$ for $2 \mathrm{~min}$. Then, the paste was kneaded using a wood stick by hand. The resulting paste stored in a plastic bag was cured at room temperature for 3 days to prepare the $\mathrm{Si}_{3} \mathrm{~N}_{4}$ bodies (SHA-1 to SHA-6). $\mathrm{Si}_{3} \mathrm{~N}_{4}$ bodies with $\alpha-\mathrm{Al}_{2} \mathrm{O}_{3}$ as a conventional sintering additive were also fabricated for comparison (SA-1 to SA-4). The fabrication procedure of the SA from the mixture was similar to that of the alumina body with HA. Table 1 summarizes the samples (SHA-1 to SHA-6, and SA-1 to SA-4) prepared for this study. Some of the resulting bodies were extruded using a single screw extruder (FM-20E, Miyazaki Iron Works Co., Ltd., Saga, Japan). The screw speed was adjusted to about $30-50 \mathrm{~mm} / \mathrm{s}$ in order to extrude the rods with $5 \mathrm{~mm}$ in diameter and tubes with $10 \mathrm{~mm}$ in outside diameter and $6 \mathrm{~mm}$ in inside diameter.

The extruded green samples were dried at room temperature for 1 week in open atmosphere then burned out at $600^{\circ} \mathrm{C}$ with $12^{\circ} \mathrm{C} / \mathrm{h}$ for $1 \mathrm{~h}$ to remove the methyl cellulose added. The burned out green samples were placed on a boron nitride substrate and put in a graphite resistant furnace (Model: FVPHP-R, Fuji Dempa Kogyo Co., Ltd., Osaka, Japan) at various temperatures between 1600 and $1800^{\circ} \mathrm{C}$ under a $\mathrm{N}_{2}$ gas pressure of $0.9 \mathrm{MPa}$. The heating rate was $10^{\circ} \mathrm{C} / \mathrm{min}$ and holding time was $4 \mathrm{~h}$.

\subsection{Sample Characterization}

"In-situ" extrusion behavior of the samples was evaluated using a simple extrusion test. ${ }^{7}$ That is, a simple cylindrical die pushes a small amount of the prepared body through a nozzle, piston force versus piston distance graph was plotted as extrusion force was exerted by a table-top testing machine (AG-1S, Shimadzu Corporation, Kyoto, Japan) at a rate of $5 \mathrm{~mm} / \mathrm{min}$ using a $5 \mathrm{kN}$ load cell. In addition, the shape of the extruded samples was observed. The bulk density of the sintered specimens was measured using the Archimedes method. The $\mathrm{Si}_{3} \mathrm{~N}_{4}$ density of $3.25 \mathrm{~g} / \mathrm{cm}^{3}$ was used for calculating the theoretical density (TD). Young's modulus of the sintered samples was measured by the pulse echo method. Vickers hardness of the samples was measured by an Instron testing machine with $10 \mathrm{~kg}$ of load applied for $10 \mathrm{~s}$. Crystalline phases of the samples were identified using X-ray diffraction (XRD) analysis. The measurements were performed using an X-ray diffractometer (RAD-RU

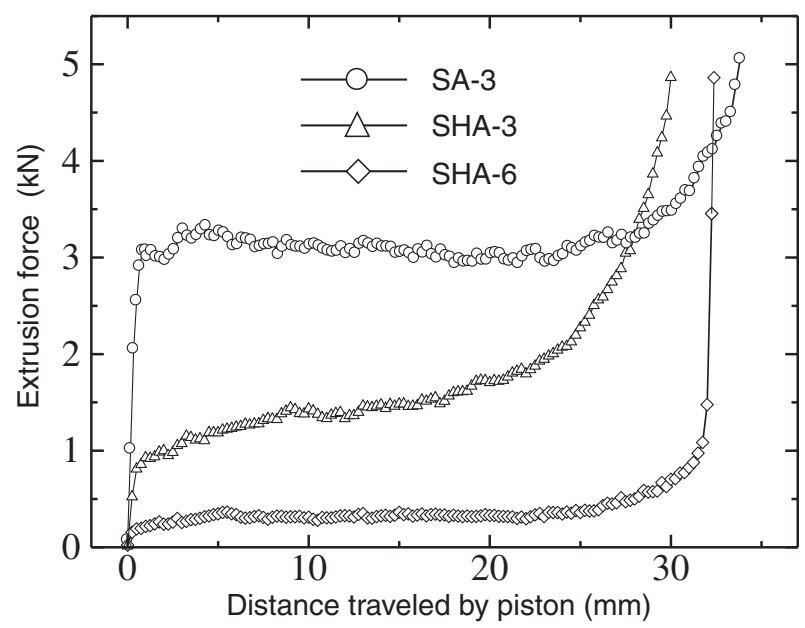

Fig. 1. Extrusion behavior of $\mathrm{Si}_{3} \mathrm{~N}_{4}$ bodies with hydraulic alumina (SHA-3 and SHA-6) and $\alpha-\mathrm{Al}_{2} \mathrm{O}_{3}$ (SA-3). SHA-3; 42.5 mass parts $\mathrm{H}_{2} \mathrm{O}$, SHA-6; 50 mass parts $\mathrm{H}_{2} \mathrm{O}$.

powder diffractometer, Rigaku Corporation, Tokyo, Japan) with $\mathrm{Cu} \mathrm{K} \alpha$ radiation $(40 \mathrm{kV}, 400 \mathrm{~mA})$. The surfaces of the polished and etched sintered samples were observed using a scanning electron microscope (SEM) (Model JSM-6340F, JEOL Ltd., Tokyo, Japan).

\section{Results and discussion}

\subsection{Sample extrusion}

The optimum composition of both SHA and SA series was determined by the simple extrusion test. In case of the SHA series, $\mathrm{Si}_{3} \mathrm{~N}_{4}$ bodies with 1 mass part of the MC (SHA-3 and SHA-6) were able to be extruded thoroughly. On the other hand, in case of the SA series, $\mathrm{Si}_{3} \mathrm{~N}_{4}$ bodies with over 3 mass parts of the MC (SA-3 and SA-4) were able to be extruded thoroughly, too. Figure 1 shows the extrusion behavior for SHA-3, SHA-6 and SA-3 bodies among the results of the extrusion tests. SHA bodies with 1 mass part of MC and 42.5-50 mass part of the water were able to be extruded stably although the extrusion forces of these bodies were lower than that of SA-3. Especially, extrusion behavior of the SHA-6 was thoroughly stable until the piston came into contact with the conical nozzle. In addition, the water separation was not observed during extrusion. Similar results were also observed during the actual extrusion with single screw extruder. Table 2 summarizes the results of the extrusion tests. $\mathrm{Si}_{3} \mathrm{~N}_{4}$ bodies with small amount of HA (SHA-3 and SHA6) had good plasticity. During the extruding process, rods and tubes without cracks and chips were prepared. Especially, SHA-6 was successfully extruded at about 1-2 MPa exit pressure without 
water separation from the body. From the extrusion results of the bodies, $\mathrm{Si}_{3} \mathrm{~N}_{4}$ bodies replacing $\alpha-\mathrm{Al}_{2} \mathrm{O}_{3}$ by $\mathrm{HA}$ were able to reduce the addition amount of the $\mathrm{MC}$ to $1 / 3$ (from 3 mass parts to 1 mass part).

Ceramic bodies with HA have good extrusion behavior under the optimum hydration conditions such as HA content, water content and curing periods. ${ }^{7), 8)}$ It is because the ceramic bodies have moderate rigidity by hydration of the HA and the hydrated HA acts as some kind of lubricant. ${ }^{15), 16)}$ However, increase in the extrusion force caused by the water separation ${ }^{17}$ ) was observed from the bodies during the simple extrusion test. ${ }^{7), 8), 16)}$ This water separation was observed not only in the bodies with small amount of HA but also in the bodies consisting of only HA and water. That is, the water separation from the bodies with HA indicates that the water retention ability of the hydrated HA is not high. Therefore, the addition of the water retention agent is necessary for the sample with HA in order to control the water separation. On the other hand, the bodies with optimum amount of the $\mathrm{MC}$ are able to be extruded thoroughly without increasing the extrusion force caused by the water separation. That is, the water retention ability of the $\mathrm{MC}$ is higher than that of the hydrated HA. From these results, $\mathrm{Si}_{3} \mathrm{~N}_{4}$ bodies with HA (SHA-3 and SHA-6) were able to be extruded thoroughly by adding a small amount (1 mass part) of MC. Then, the added MC acted as water retention agent effectively in the bodies with HA. However, in case of SHA-3, though water content of SHA-3 was less than that of SHA-6, increase in the extrusion force caused by the water separation was observed as shown in Fig. 1. This is because water in the body that works as a lubricant was not enough. In this study, it is not clear whether the addition of both $\mathrm{HA}$ and $\mathrm{MC}$ is additive action or synergistic action.

\subsection{Drying and sintering}

Table 3 summarizes the bulk density and relative density of the sintered samples together with Young's modulus and Vickers hardness of the sintered specimens. SHA-3 and SHA-6 had lower density than SA-3 when they were sintered at $1600^{\circ} \mathrm{C}$. The main reason is due to $\gamma-\mathrm{Al}_{2} \mathrm{O}_{3}$ formation in the SHA samples. ${ }^{18)-20)}$ But, these samples achieved more than almost 99\% TD after sintering at over $1700^{\circ} \mathrm{C}$ due to the effect of $\mathrm{HA}$ as a sintering additive. The value of Young's modulus and Vickers hardness of the sintered SHA-3 and SHA-6 were almost identical to those of the sintered SA-3, that is, Young's modulus is $>300 \mathrm{GPa}$, and $\mathrm{Hv}$ is $>1330$. Figure 2 shows the $\mathrm{X}$-ray diffraction profiles of the sintered SHA-6 sample. There was no difference in the crystalline phase in the sample with HA (SHA-6) and the sample with $\alpha$ -

Table 2. Extrusion results of the samples

\begin{tabular}{lll}
\hline $\begin{array}{c}\text { Sample } \\
\text { name }\end{array}$ & \multicolumn{1}{c}{$\begin{array}{c}\text { Extrusion pressure } \\
\text { /MPa }\end{array}$} & \multicolumn{1}{c}{ Comments } \\
\hline SHA-3 & $>3.5-5.5$ (rods) & Water separation (appreciably) \\
SHA-6 & $1-2$ (rods, tubes) & Very successful. No water separation \\
SA-3 & 6 (rods), 5-6 (tubes) & Excellent \\
\hline
\end{tabular}

$\mathrm{Al}_{2} \mathrm{O}_{3}$ (SA-3) sintered at 1700 and $1800^{\circ} \mathrm{C} . \alpha-\mathrm{Si}_{3} \mathrm{~N}_{4}$ was not identified at $1700^{\circ} \mathrm{C}$, and both $\mathrm{Y}_{2} \mathrm{SiAlO}_{5} \mathrm{~N}$ and $\mathrm{Y}_{10} \mathrm{Al}_{2} \mathrm{Si}_{3} \mathrm{O}_{18} \mathrm{~N}_{4}$ were appeared at the grain-boundary phase at $1800^{\circ} \mathrm{C}$. Figure 3 shows the extruded $\mathrm{Si}_{3} \mathrm{~N}_{4}$ tubes prepared from SHA- 6 bodies after sintering. These tubes have no cracks and chips.

During the extruding, drying, and sintering processes, there is a possibility that micro cracks are formed in the samples. The value of Young's modulus measured by pulse echo method is extremely sensitive to the micro cracks in the sintered samples. ${ }^{21)}$ As seen from the Table 3, Young's modulus of the SHA-3 and SHA-6 was almost the same as SA-3. This result indicates that the micro crack formation was controlled by adding a small amount of MC even in the addition of a small amount of HA. That is, workability of the SHA bodies is the same as that of the SA bodies. Figure 4 shows SEM micrograph of the extruded SHA-6

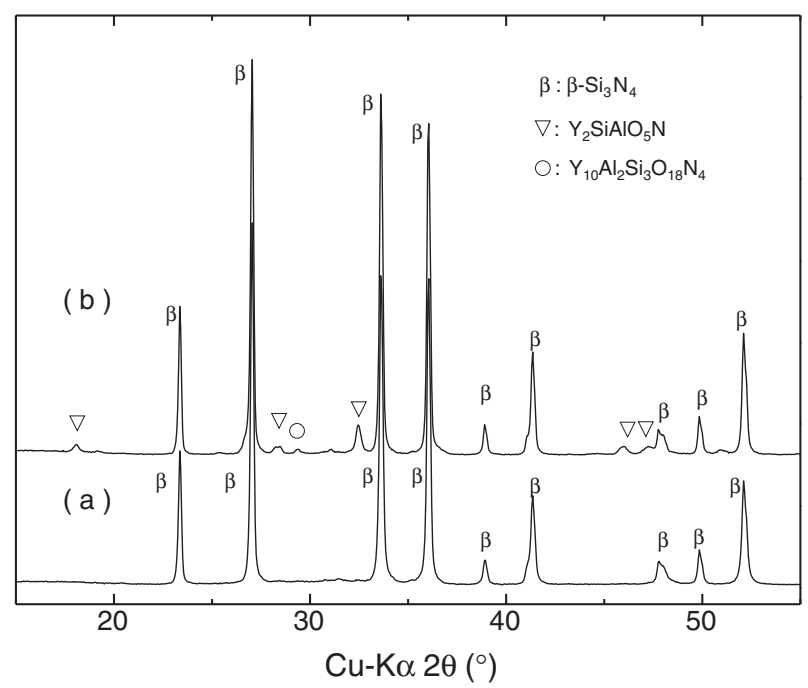

Fig. 2. X-ray diffraction profiles of the sample with SHA-6 sintered at $1700^{\circ} \mathrm{C}$ (a) and $1800^{\circ} \mathrm{C}$ (b) for $4 \mathrm{~h}$.

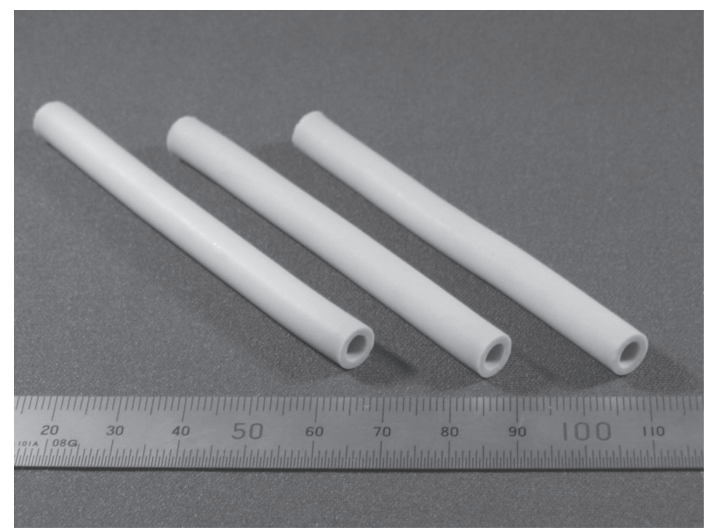

Fig. 3. $\mathrm{Si}_{3} \mathrm{~N}_{4}$ tubes prepared by extrusion of SHA- 6 then sintered at $1800^{\circ} \mathrm{C}$ for $4 \mathrm{~h}$.

Table 3. Bulk densities, theoretical densities and some physical properties of the obtained sintered samples

\begin{tabular}{lccccc}
\hline & \multicolumn{4}{c}{ Sintering condition } \\
\cline { 2 - 6 } Samples & $1600^{\circ} \mathrm{C}-4 \mathrm{~h}$ & $\begin{array}{c}1700^{\circ} \mathrm{C}-4 \mathrm{~h} \\
\text { Dbulk, } \mathrm{g} / \mathrm{cm}^{3}(\mathrm{TD}, \%)\end{array}$ & $\begin{array}{c}1800^{\circ} \mathrm{C}-4 \mathrm{~h} \\
\text { Young's modulus } / \mathrm{GPa}\end{array}$ & $\mathrm{Hv}$ \\
\hline SHA-3 & $1.44(44.3 \%)$ & $3.22(>99 \%)$ & $3.23(>99 \%)$ & 305 & $1330-1370$ \\
SHA-6 & $1.49(45.8 \%)$ & $3.22(>99 \%)$ & $3.21(98.8 \%)$ & 306 & $1330-1370$ \\
SA-3 & $1.80(55.4 \%)$ & $3.21(98.8 \%)$ & $3.23(>99 \%)$ & 305 & $1330-1370$ \\
\hline
\end{tabular}




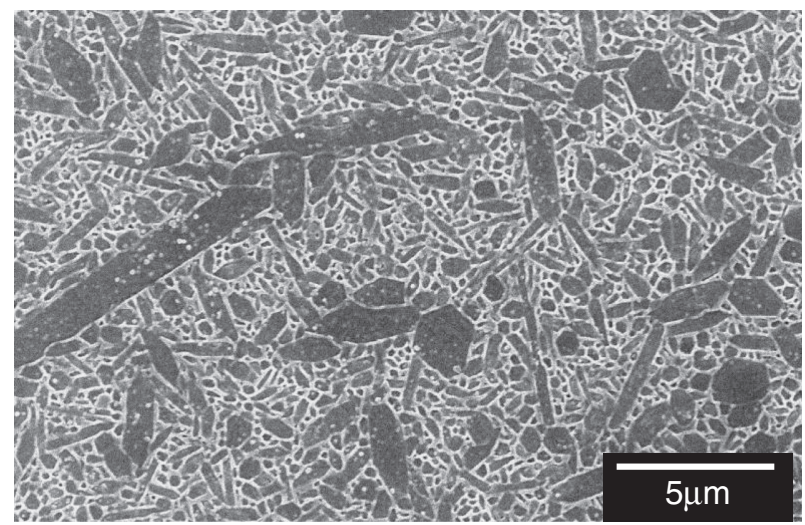

Fig. 4. SEM micrograph of polished and etched surface of $\mathrm{Si}_{3} \mathrm{~N}_{4}$ prepared by extrusion of SHA- 6 then sintered at $1800^{\circ} \mathrm{C}$ for $4 \mathrm{~h}$.

sample sintered at $1800^{\circ} \mathrm{C}$ for $4 \mathrm{~h}$. Sintered SHA-6 sample had both dense and typical bimodal microstructure with rod-like $\beta$ $\mathrm{Si}_{3} \mathrm{~N}_{4}$ grains on the order of less than $1 \mu \mathrm{m}$ in size and a few $\beta$ $\mathrm{Si}_{3} \mathrm{~N}_{4}$ grains more than $2-3 \mu \mathrm{m}$ in width, and without any pores. These results indicate that dense $\mathrm{Si}_{3} \mathrm{~N}_{4}$ ceramics with similar mechanical properties can be prepared without using the conventional organic binder and sintering additive. In other words, HA acts as inorganic binder for extrusion and sintering additive for $\mathrm{Si}_{3} \mathrm{~N}_{4}$.

\section{Conclusions}

$\mathrm{HA}$ addition proposed as both a new inorganic binder for extrusion and a sintering additive for $\mathrm{Si}_{3} \mathrm{~N}_{4}$ ceramics was studied using $\mathrm{Si}_{3} \mathrm{~N}_{4}$ bodies with $\alpha-\mathrm{Al}_{2} \mathrm{O}_{3}$ and $\mathrm{Y}_{2} \mathrm{O}_{3}$ as sintering additives. Replacing $\alpha-\mathrm{Al}_{2} \mathrm{O}_{3}$ by $\mathrm{HA}$ in $\mathrm{Si}_{3} \mathrm{~N}_{4}$ bodies assisted imparting the plasticity necessary for easy extrusion, and at the same time reduced the amount of the organic binder methyl cellulose to $1 / 3$. Sintered samples with HA reached $99 \%$ of theoretical density after sintering above $1700^{\circ} \mathrm{C}$ as well as those with conventional $\alpha-\mathrm{Al}_{2} \mathrm{O}_{3}-\mathrm{Y}_{2} \mathrm{O}_{3}$ sintering additives with methyl cellulose. Dense $\mathrm{Si}_{3} \mathrm{~N}_{4}$ samples prepared using $\mathrm{HA}$ and those prepared using conventional additives had similar mechanical properties, that is, Young's modulus $>300 \mathrm{GPa}$ and $\mathrm{H}_{\mathrm{v}}>1330$. These results indicate that HA acts as inorganic green binder for extrusion and a sintering additive for $\mathrm{Si}_{3} \mathrm{~N}_{4}$ ceramics.

\section{References}

1) A. R. Teter, Ceram. Age, 82, 30-32 (1966).

2) A. L. Salamone and J. S. Reed, Am. Ceram. Soc. Bull., 58, 1175-1178 (1979).

3) N. Sarker and G. K. Greminger, Jr., Am. Ceram. Soc. Bull., 62, 1280-1284 (1983).

4) J. E. Schuetz, Am. Ceram. Soc. Bull., 65, 1556-1559 (1986).

5) J. K. Wright, R. M. Thomson and J. R. G. Evans, J. Mater. Sci., 25, 149-156 (1990).

6) Y. Chen, A. Burbidge and J. Bridgewater, J. Am. Ceram. Soc., 80, 1841-1850 (1997).

7) T. Nagaoka, K. Sato, Y. Hotta, T. Tsugoshi and K. Watari, J. Ceram. Soc. Japan, 115, 191-194 (2007).

8) T. Nagaoka, C. Duran, T. Isobe, Y. Hotta and K. Watari, J. Am. Ceram. Soc., 90, 3998-4001 (2007).

9) G. G. Deely, J. M. Herbert and N. C. Moore, Powder Metall., 8, 145-151 (1961).

10) A. Tsuge, K. Nishida and M. Komatsu, J. Am. Ceram. Soc., 58, 323-326 (1975).

11) N. Hirosaki, A. Okada and K. Matoba, J. Am. Ceram. Soc., 71, c-144-c-147 (1988).

12) W. D. Kingery, J. Appl. Phys., 30, 301-310 (1959).

13) M. Maeda, M. Suzuki and Y. Shibasaki, J. Ceram. Soc. Japan, 105, 1155-1158 (1997) [in Japanese].

14) G. Jiang, J. Yang, J. Gao and K. Niihara, Mater. Charact., 60, 456-460 (2009).

15) M. Polat, K. Sato, T. Nagaoka and K. Watari, J. Colloid Interface Sci., 304, 378-387 (2006).

16) T. Nagaoka, M. Polat, K. Sato, Y. Hotta and K. Watari, Proc., 10th ECerS Conf., Ed. by J. G. Geinrich and C. Aneziris, Goller Verlag, Barden-Barden, pp. 393-397 (2007).

17) J. Davies and J. G. P. Binner, J. Eur. Ceram. Soc., 20, 15691577 (2000).

18) D. I. Matkim, W. Munro and T. M. Valentine, J. Mater. Sci., 6, 974-980 (1971).

19) S. J. Wilson, J. Solid State Chem., 30, 247-255 (1979).

20) M. Kumagai and G. L. Messing, J. Am. Ceram. Soc., 68, 500505 (1985).

21) T. Nagaoka, M. Yasuoka, K. Hirao and S. Kanzaki, J. Ceram. Soc. Japan, 100, 617-620 (1992). 